\title{
A INÉRCIA LEGISLATIVA: A NECESSIDADE DE PROTEÇÃO LEGAL DAS MINORIAS SEXUAIS
}

\author{
Gabriela Soares Balestero* \\ Alexandre Gustavo Melo Franco Bahia**
}

\begin{abstract}
Época triste a nossa, em que é mais difícil quebrar um preconceito do que um átomo. (Albert Einstein)

Em nome de uma moral sexual dita civilizatória, muita injustiça tem sido cometida. O Direito, como instrumento ideológico e de poder, em nome da moral e dos bons costumes, já excluiu muitos do laço social. (Rodrigo da Cunha Pereira. A sexualidade vista pelos tribunais).
\end{abstract}

\section{RESUMO}

O presente estudo trata da necessidade de dar proteção legal às minorias sexuais no que tange a criminalização de práticas discriminatórias. Na Constituinte de 1988, ao proibir discriminação de qualquer tipo, o Congresso legalizou "ser" homossexual. Desde então, contudo, pouca coisa se fez no Legislativo para combater o preconceito com base na orientação sexual. Em sua atividade, os congressistas continuam a desconsiderar as conseqüências práticas da vivência plena da homossexualidade, sendo que tal fato pode ser observado diante da inércia na aprovação do Projeto de Lei n. 122 que visa a criminalização da homofobia. Ser hétero ou homossexual não deveria acarretar qualquer diferença em termos de tratamento pelo Estado, pois sem dúvida deve haver o respeito aos princípios constitucionais de igualdade, da dignidade da pessoa humana, aliados aos demais valores fundamentais, e princípios gerais que regem o direito brasileiro.

Palavras-chave: Criminalização. Homoafetividade. Homofobia. Igualdade. Proteção legal.

\section{INTRODUÇÃO}

A Constituição Federal de 1988 proibiu a discriminação de qualquer tipo seja por raça, cor e orientação sexual. Nesse sentido, pode-se considerar que houver a legalização do "ser" homossexual, contudo, pouca coisa se fez no Legislativo no que concerne ao combate do preconceito com base na orientação sexual.

Os congressistas continuam desprezando a necessidade de dar proteção legal às conseqüências da vivência prática da homossexualidade, pois, a orientação sexual do ser humano não deve acarretar qualquer diferença de tratamento pelo Estado.

É necessário derrubar o preconceito e buscar o reconhecimento jurídico constitucional do diferente bem como sua proteção legal, criminalizando práticas 
discriminatórias quanto à orientação sexual, que foi objeto do Projeto de Lei de $\mathrm{n}$. 122 paralisado no Congresso Nacional.

Em um Estado Democrático de Direito, os processos de reconhecimento e inclusão são constantes. O sistema de direitos fundamentais deve estar apto a detectar que certa minoria não possui o devido reconhecimento - violando-lhe o direito de igual tratamento em sua diferença - e, pois, criar os meios necessários para incluí-la. Nesse sentido, mostra-se premente a necessidade de proteção legal das minorias sexuais (LGBT) que estão colocadas à margem do descaso dos governantes, da violência e do preconceito.

Eis o objetivo do presente estudo.

\section{DO CONCEITO: A HOMOAFETIVIDADE}

O vocábulo homossexualidade foi atribuído ao médico húngaro Karoly Benkert no ano de 1869, formado pela raiz da palavra grega homo, que significa semelhante e pela palavra sexus, significando, portanto, o termo "sexualidade semelhante". Em 1911, E.Harsh-Haak cunhou a expressão homoerotismo na tentativa de acabar com o preconceito e valorizar as experiências afetivo - homossexuais.

Porém infelizmente ainda hoje é usada a palavra perversão para designar as relações sexuais fora da heterossexualidade. Na França ainda é usada a expressão inversão sexual já que entendem que as qualidades morais do indivíduo permanecem havendo apenas uma alteração em sua conduta sexual.

Maria Berenice Dias, ao criar a expressão homoafetividade no ano 2000 procurou "evidenciar que as uniões de pessoas do mesmo sexo nada mais são do que vínculos de afetividade"1. Já Enézio de Deus Silva Júnior ${ }^{2}$ prefere a expressão homoessência, termo introduzido pela Associação Brasileira de Estudos da Homocultura que estuda as minorias sexuais ${ }^{3}$.

Segundo Paulo Roberto lotti Vecchiatti "a homossexualidade é o sentimento de amor romântico por uma pessoa do mesmo sexo. Não constitui doença, desvio psicológico, perversão nem nada do gênero".

Nesse sentido, a homossexualidade ${ }^{5}$ não é uma doença, nem uma opção e sim uma descoberta pessoal em um determinado momento da vida.

Mais importante é a constatação de que muito mais prejudicial o que a homossexualidade em si é o avassalador estigma social de que são alvo gays, lésbicas, bissexuais, transexuais, travestis e transgêneros. São indivíduos que experimentam sofrimento originado na intolerância e no injustificado preconceito social. A busca pela despatologização da homossexualidade visa a defini-la como simples variante natural da expressão sexual humana, um comportamento que determina uma maneira de viver diferente. ${ }^{6}$ 
A prática ${ }^{7}$ da homoafetividade sempre esteve prevista na história da humanidade pelo fato de ser natural o desejo sexual e o carinho por pessoas do mesmo sexo. Porém ainda hoje ela é apenas tolerada e não completamente aceita ${ }^{8}$.

Infelizmente, os efeitos jurídicos das relações homoafetivas ainda são poucos, pois há projetos de lei apresentados no Congresso Nacional que sequer foram votados $^{9}$ e o que se tem conseguido até hoje são decisões judiciais e instruções normativas. Contudo, a omissão legislativa não pode servir de obstáculo à outorga de direitos e deveres nas relações homoafetivas.

Portanto, a homoafetividade deve ser inserida no conceito de entidade familiar $^{10}$, pois se ainda não há a possibilidade do casamento ${ }^{11}$, as mesmas normas que regulamentam a união estável devem ser aplicadas, gerando inclusive efeitos patrimoniais e sucessórios no caso de falecimento de um dos companheiros ${ }^{12}$.

\begin{abstract}
Ou seja, os princípios constitucionais da isonomia e da dignidade da pessoa humana, que possuem a qualidades de efetivas normas de eficácia plena, devem ser usados como paradigma na interpretação tanto das normas constitucionais quanto das infraconstitucionais. Afinal, ditos princípios demonstram a vontade primordial do constituinte, a saber, a proibição de discriminações arbitrárias, donde só se pode ter como possível a extensão dos regimes jurídicos do casamento civil e da união estável aos casais homoafetivos. ${ }^{13}$
\end{abstract}

Nesse sentido, é necessária uma interpretação conforme à Constituição Federal, dispositivos que versam sobre a família, o casamento civil e a união estável somente podem ser interpretados de maneira a permitir o reconhecimento ${ }^{14}$ do status jurídico - familiar das uniões homoafetivas.

A omissão legislativa em regulamentar a homoafetividade bem como prever a punibilidade à homofobia (popularmente conhecida como aversão, repúdio aos homossexuais) parece configurar uma tentativa infrutífera de exclusão de possibilidade de reconhecimento de direitos e de efeitos jurídicos de tais relações, tendo em vista que a ausência de previsão legal não implica na impossibilidade de aplicação dos princípios constitucionais da isonomia, dignidade da pessoa humana.

\begin{abstract}
Apesar da urgência quanto ao tema - há que se recordar, de antemão, que, "apenas no Brasil, a cada três dias uma pessoa é assassinada em virtude de ódio motivado na orientação sexual" (RIOS, 2001, p.279,280) -, o que mostraremos é que, no nível federal interno, pouco ou quase nada de concreto tem sido feito, o que contrasta com ações do Brasil como entidade de Direito Público Externo, em Documentos Internacionais de que o país é signatário, algumas delas inclusive propostas por ele. De outro lado, os Municípios ( e também os Estados) vêm mostrando ações mais diretas. ${ }^{15}$
\end{abstract}

Nesse sentido, o direito à não discriminação contra a população LBGT é um direito fundamental e, portanto, deve ser alvo de amparo e de proteção do poder público. 


\section{O PROJETO DE LEI N. 122/2006 E A INÉRCIA DO CONGRESSO NACIONAL}

Primeiramente, verifica-se que a Constituição Federal de 1988 prevê no art. 3o como objetivo fundamental da República Federativa do Brasil promover o bem de todos, sem preconceitos de origem, raça, sexo, cor, idade e quaisquer outras formas de discriminação.

Segundo Roger Raupp Rios ${ }^{16}$ "o direito de igualdade decorre imediatamente do princípio da primazia da lei no Estado de Direito [...]independentemente das peculiares circunstâncias de cada situação concreta e da situação pessoal dos destinatários da norma jurídica."

A Lei n. 11.340 de 07 de agosto de 2006, apelidada de Lei Maria da Penha criou mecanismos para coibir a violência doméstica e familiar contra a mulher, nos termos do $\S 8^{\circ}$ do art. 226 da Constituição Federal, da Convenção sobre a Eliminação de Todas as Formas de Discriminação contra as Mulheres e da Convenção Interamericana para Prevenir, Punir e Erradicar a Violência contra a Mulher.

O projeto foi elaborado por um grupo interministerial a partir de um anteprojeto de organizações não-governamentais baseado no caso da biofarmacêutica Maria da Penha Maia vítima de violência doméstica ocasionada pelo seu marido que foi condenado pela Comissão Interamericana dos Direitos Humanos da Organização dos Estados Americanos (OEA). O governo federal o enviou ao Congresso Nacional no dia 25 de novembro de 2004. Lá, ele se transformou no Projeto de Lei de Conversão 37/2006, aprovado e sancionado dando origem à Lei n. 11.340 de 07 de agosto de 2006.

Nesse passo, o Estado criou mecanismos de coibir a violência doméstica contra a mulher no âmbito das relações domésticas, dando amparo legal protetivo à figura feminina.

No dia 20 de julho de 2010 foi sancionado o Estatuto da Igualdade Racial ${ }^{17}$ que estimula e cria ações afirmativas, políticas públicas em defesa dos que sofrem preconceito ou discriminação em função de sua etnia, raça ou cor, de maneira a darIhes igualdade de oportunidades, sendo, portanto, um grande avanço.

A Lei n. 12.015, de 7 de agosto de 2009, trouxe importantes modificações no Título VI da Parte Especial do Código Penal que antes era chamada de "Crimes contra os Costumes", que agora passou a ser "Dos Crimes Contra a Dignidade Sexual".

A sexualidade humana não pode ser reduzida a parâmetros, pois é um bem jurídico importante, mas, sobretudo, é atributo do ser humano, irredutível, indominável irreprimível, indeterminável, a não ser pela própria liberdade individual e por isso, cabe ao direito assegurar a toda pessoa o direito de expressar livremente a sua sexualidade, qualquer que seja sua orientação sexual. Para isso deve impedir que a sexualidade seja exercida sob ação de qualquer espécie de violência, moral ou física. 
Entretanto, apesar de tantos avanços legais em proteção à discriminação e qualquer tipo de violência à mulher, à origem étnica, à raça e à cor, incluindo inclusive a reforma do Código Penal, há ainda um déficit de representação política e de proteção legal aos milhares de cidadãos homoafetivos (LGBT) brasileiros.

$\mathrm{Na}$ Constituinte de 1988, ao proibir discriminação de qualquer tipo, o Congresso legalizou "ser" homossexual. Desde então, contudo, pouca coisa se fez no Legislativo para combater o preconceito com base na orientação sexual. Em sua atividade, os congressistas continuam a desconsiderar as conseqüências práticas da vivência plena da homossexualidade. Ser hétero ou homossexual não deveria acarretar qualquer diferença em termos de tratamento pelo Estado. Mas, na prática, acarreta. ${ }^{18}$

O Projeto de Lei Complementar n. 122/2006 oriundo da Associação Brasileira de Gays, Lésbicas, Bissexuais, Transexuais e Travestis (ABGLT) ainda não foi votado pelo Congresso Nacional. Ele prevê que serão punidos, na forma da lei os crimes resultantes de discriminação, ou preconceito de raça, cor, etnia, religião, procedência nacional, gênero, sexo, orientação sexual e identidade de gênero, incluindo inclusive a penalização da proibição da manifestação da afetividade em locais públicos.

Esse projeto equipara a discriminação por orientação sexual e identidade de gênero à discriminação de raça, cor, etnia, religião, procedência nacional, sexo e gênero, sendo que os autores de tais crimes podem ser punidos com pena de reclusão e multa. Para cada modo de discriminação há uma pena específica.

Contudo, verifica-se o descaso do legislador federal brasileiro em relação às minorias sexuais é tão grande que até hoje, no país, a homofobia ${ }^{19}$ não é sancionada como crime, ou seja, se depender do Congresso Nacional os homoafetivos brasileiros (LGBT) terão uma cidadania incompleta.

Ao contrário do que ocorre na esfera municipal ${ }^{20}$, em nível federal o Legislativo federal vem demonstrando completo desprezo ${ }^{21}$ no reconhecimento dos direitos das minorias sexuais ${ }^{22}$.

Segundo Relatório da ILGA, em 2008 oitenta e seis países, membros das Nações Unidas, "ainda criminalizavam as relações sexuais consensuais entre adultos do mesmo sexo (..). Entre eles, 7 apresentam dispositivos legais com penalidade de morte como forma de punição" (OTTOSSON, 2008, p.4). A despeito dos méritos da Resolução e da urgência na aprovação de atos internacionais vinculantes, é importante anotar que ainda não existe nenhuma Convenção Internacional sobre o tema. ${ }^{23}$

É necessário, portanto, derrubar o preconceito e reconhecer constitucionalmente a homoafetividade como família e criminalizar práticas discriminatórias, de maneira a proporcionar o reconhecimento de direitos e de respeitar cada indivíduo em particular, independentemente da orientação sexual que ele possua. 
Consoante Roger Raupp Rios ${ }^{24}$ "o Brasil é conhecido como um dos países em que há o maior número de assassinatos por orientação sexual [...] de que a cada dois dias uma pessoa é assassinada no Brasil em função de sua orientação sexual, informação absolutamente avassaladora".

\begin{abstract}
Mas a homofobia no Brasil também mata: um homossexual a cada três dias é morto de forma violenta em razão de sua sexualidade. Isso coloca o Brasil no topo dos mais homofóbicos do mundo. Dia 01/07 completa uma semana do assassinato bárbaro de Alexandre Ivo, um adolescente de 14 anos morto com pauladas e enforcamento em São Gonçalo - RJ por skinheads - grupo que prega a "fobia" contra gays, negros, nordestinos, etc. O jovem voltava para casa. Enquanto isso o Congresso brasileiro tem em mãos desde 2006 um Projeto de Lei que inclui os homossexuais entre os protegidos contra o crime de racismo e discriminação, impondo penas mais severas que as hoje existentes, mas, mais do que isso, reconhecendo ser este um problema, uma questão que deve merecer tratamento específico por parte do Estado. Ao que tudo indica, entretanto, nossos parlamentares não estão muito interessados em aprovar o PL este ano - ou, quiçá, em qualquer época, inclusive porque setores religiosos são contra o projeto, argumentando que a liberdade religiosa seria limitada, o que não nos parece fazer sentido, pois, um discurso que seja estritamente religioso pode/deve ser protegido pela Constituição; entretanto, se alguém em nome de Deus (?) promove bullying, discurso de ódio, tais atitudes/manifestações sempre foram ilícitas. ${ }^{25}$
\end{abstract}

Nesse sentido reconhecer a homofobia como um problema e criminalizar práticas discriminatórias quando à orientação sexual é uma via extremamente fecunda para o funcionamento da própria democracia que deve ser constituída pela adesão dos princípios da liberdade e da igualdade, sendo base para uma cidadania democrática ${ }^{26}$.

A ausência de proteção legal às minorias sexuais traz o seguinte questionamento: qual o grau de exclusão social que um sistema considerado democrático, como o brasileiro, pode aceitar?

A exclusão social ${ }^{27}$ acarreta a degradação do ser humano em suas manifestações e o afastamento das minorias da discussão política e do amparo aos seus direitos.

Segundo Stuart Mill ${ }^{28}$, "É um grande desencorajamento para um indivíduo, e ainda maior para uma classe, sentir-se fora da constituição; sentir-se reduzido a pleitear seus direitos, do lado de fora da porta, aos árbitros de seu destino, sem que o chamem para consultá-lo." Ou seja, deve haver um processo de integração das minorias para que elas sejam amparadas pelo ordenamento jurídico.

Ora, nada é mais certo do que o fato de suprimir virtualmente a minoria não ser uma conseqüência nem necessária e nem natural da liberdade; que, longe de ter qualquer ligação com a democracia, tal fato opõe-se diametralmente ao primeiro princípio desta, ou seja, representação proporcional em números. É uma parte essencial da democracia que as minorias devam ser adequadamente representadas. Nenhuma democracia verdadeira será possível exceto uma falsa demonstração dela sem essas minorias. $^{29}$ 
Assim, o Estado Brasileiro tem o dever de zelar pela defesa e proteção das minorias que sofrem preconceito em decorrência de sua orientação sexual de maneira a efetivar o caráter garantidor e protetivo previsto no art. 5, parágrafos segundo e terceiro da Constituição Federal.

\begin{abstract}
Essa exigência não visa em primeira linha ao igualamento das condições sociais de vida, mas sim à defesa da integridade de formas de vida e tradições com as quais os membros de grupos discriminados possam identificar-se. Normalmente ocorre que o não reconhecimento cultural coincide com condições rudes de demérito social, de modo que as duas coisas se fortalecem de maneira cumulativa. Polêmico é definir se a exigência 2 resulta da exigência 1 - ou seja, se ela resulta do princípio de que deve haver igual respeito por cada indivíduo em particular - ou se essas duas exigências têm mesmo de colidir, ao menos em alguns casos. ${ }^{30}$
\end{abstract}

É necessário o tratamento eqüitativo de proteção legal às minorias sexuais com uma política de respeito às diferenças, tendo o Estado o papel de fomentar essa política de proteção e de reconhecimento ${ }^{31}$.

O sistema de direitos não pode desprezar as diferenças ${ }^{32}$, sendo necessária uma política de reconhecimento que preserve a integridade das minorias sexuais, até mesmo em suas condições mais vitais garantidoras de sua própria identidade.

Uma leitura "liberal" do sistema de direitos que ignore essa relação não tem
saída senão entender erroneamente o universalismo dos direitos
fundamentais como nivelamento abstrato de diferenças, e de diferenças
tanto culturais quanto sociais. Caso se queira tornar o sistema de direitos
efetivo por via democrática, é preciso que se considerem as diferenças com
uma sensibilidade sempre maior para o contexto. Ontem como hoje, a
universalização dos direitos, sistema que logra manter segura a integridade
dos sujeitos jurídicos, mas não sem um tratamento rigidamente igualitário (e
monitorado pelos próprios cidadãos) dos contextos de vida de cada um, os
quais originam sua própria identidade individual. Caso se corrija a forma
seletiva com que a teoria dos direitos faz sua leitura da realidade, e caso se
propicie com isso, tal compreensão democrática da efetivação dos direitos
fundamentais, então nem se precisará contrapor ao lliberalismo 1 reduzido",
um modelo que introduza direitos coletivos estranhos ao próprio sistema.

A arquitetônica do Estado de Direito que é muito rica em pressupostos visa a igualar $^{34}$ juridicamente e proporcionar o reconhecimento do diferente, ou seja, das coletividades que se distinguem umas das outras, seja pela sua origem étnica, pela tradição, pela forma de vida, ou até mesmo, como ocorre na situação analisada, pela orientação sexual ${ }^{35}$.

Com isso, a questão sobre o 'direito' ou os 'direitos' de minorias ofendidas e maltratadas ganha um sentido jurídico. Decisões políticas servem-se da forma de regulamentação do direito positivo para tornarem-se efetivos em sociedades complexas...Uma ordem jurídica é legítima quando assegura por igual a autonomia de todos os cidadãos. E os cidadãos só são autônomos quando os destinatários do direito podem ao mesmo tempo 
entender-se a si mesmos como autores do direito. E tais autores só são livres como participantes de processos legislativos regrados de tal maneira e cumpridos sob tais formas de comunicação que todos possam supor que regras firmadas desse modo mereçam concordância geral e motivada pela razão. Do ponto de vista normativo, não há Estado de direito sem democracia. Por outro lado, como o próprio processo democrático precisa ser institucionalizado juridicamente, o princípio da soberania dos povos exige, ao inverso, o respeito a direitos fundamentais sem os quais simplesmente não pode haver um direito legítimo: em primeira linha o direito a liberdades de ação subjetivas iguais, que por sua vez pressupõe uma defesa jurídica individual e abrangente. ${ }^{36}$

A suposta neutralidade do direito é analisada como se questões de reconhecimento jurídico e constitucional tivessem que ser afastadas do direito, suprimindo qualquer discussão por serem inacessíveis a uma regulamentação jurídica imparcial.

Segundo Jürgen Habermas" ${ }^{37}$ "é preciso poder entender as decisões do legislador político como efetivação do sistema de direitos, e suas políticas como configuração desse mesmo sistema".

E o conceito de 'exclusão social' não diz apenas respeito à pobreza ou marginalização; mas à conhecida e fatal 'reação em cadeia da exclusão' que se estende da exclusão econômica/financeira até a exclusão jurídica (negação da proteção jurídica e dos direitos humanos etc.), passando pela exclusão social, sócio-cultural e política. ${ }^{38}$

A configuração democrática do nosso sistema deve incluir e amparar o diferente, igualando direitos, de modo a não apenas demarcarmos ou delimitarmos políticas e sim atingirmos fins coletivos reconhecendo direitos.

O poder comunicativo só se forma naqueles espaços públicos que produzem relações intersubjetivas na base do reconhecimento mútuo e que possibilitam o uso das liberdades comunicativas - que possibilitam, portanto, posicionamentos sim/não relativamente a temas, razões (Grunde) e informações livremente flutuantes. ${ }^{39}$

Nesse passo, o reconhecimento de direitos migrou para a própria práxis ao constatarmos que no direito positivo e no próprio Estado Democrático de Direito há princípios que possuem uma fundamentação pós - convencional e que devem ser ajustados a uma consciência pública de uma cultura política liberal. Em um Estado Democrático de Direito todos devem ser portadores dos mesmos direitos ${ }^{40}$.

As lutas pelo reconhecimento no estado democrático só possuem força legitimante na medida em que todos os grupos tenham acesso à esfera pública política, tenham voz ativa e possam articular suas necessidades, e ninguém seja marginalizado ou excluído. Já deste ponto de vista da representação e da "qualificação cívica" é importante assegurar as premissas efetivas para o gozo em igualdade de chances dos direitos formalmente iguais. Tal não se aplica apenas aos direitos de participação política, mas também aos de participação social e aos direitos individuais, 
pois ninguém pode agir politicamente de forma autônoma se as condições de emergência de sua autonomia privada não estiverem asseguradas. Neste contexto, sou também favorável ao estabelecimento de cotas; por exemplo, por uma política de preferred biring em todos os setores de formação e de ocupação nos quais apenas por esta via possa ser assegurado o "justo valor" dos direitos iguais para grupos estrutural e historicamente desfavorecidos. Estas medidas devem produzir um "efeito recuperativo" e têm por isso caráter temporário. ${ }^{41}$

A proteção legal dos homoafetivos implica em considerar o outro portador dos mesmos direitos ${ }^{42}$. Portanto, o princípio da igualdade está atrelado ao princípio da antidiscriminação ${ }^{43}$, da anti-subjugação, se relacionando com 0 princípio da dignidade da pessoa humana, estabelecendo que se deve conferir iguais direitos, iguais valores às pessoas, independentemente de sua condição, ou de sua orientação sexual.

Segundo Rainer Forst ${ }^{44}$ o direito possui uma tripla função “a) assegurar um espaço formal para a possibilidade de formar uma identidade própria; b) reconhecer e proteger identidades particulares com determinadas conseqüências jurídicas; c) manter juridicamente os limites morais desse reconhecimento".

\begin{abstract}
O mais importante, contudo, é o seguinte; se MacLintyre fizesse a distinção entre as várias comunidades que ele listou, então viriam à tona as diferentes relações de reconhecimento recíproco que distinguem as comunidades éticas das comunidades políticas e morais (ibidem, p. 86). Então, mostrar-se-ia que a "guerra civil" diagnosticada por ele somente ocorreria caso os membros das comunidades éticas reconhecessem apenas seus iguais e não demonstrassem respeito por "outras" pessoas enquanto parceiros do direito, concidadãos ou pessoas morais - portanto, que não compartilham de sua própria concepção do bem. Esse respeito não é, porém, uma exigência ética, mas moral: a de reconhecer os outros como iguais, apesar das suas diferenças. ${ }^{45}$
\end{abstract}

O Estado Constitucional Democrático representa o reconhecimento de direitos, permitindo que os endereçados pela justiça se sintam como os seus autores e, nesse sentido, desconsiderar o outro como portador dos mesmos direitos é violar condição de legitimação essencial da democracia.

Não pode existir perseguição e discriminação sistemáticas que privem as chances dos membros de grupos menos privilegiados de efetivamente utilizar os direitos formais divididos igualmente. É na dialética da igualdade jurídica e desigualdade fática que se fundamenta a tarefa do Estado social de atuar no sentido de garantir as condições de vida - em termos sociais, tecnológicos e ecológicos - que tornam possível um uso igualitário dos direitos civis divididos de modo igual. O intervencionismo do Estado social, fundamentado na própria Constituição, expande a autolegislação democrática dos cidadãos de um Estado nacional no sentido de uma autocondução democrática de uma sociedade definida como Estado nacional. ${ }^{46^{3}}$

A aprovação da PLC de n. 122/2006 criminalizando práticas discriminatórias em decorrência da orientação sexual proporcionará maior justiça social, pois todos 
possuem o direito a um tratamento igual, a ser tratado como igual ${ }^{47}$, sendo este um direito fundamental.

\begin{abstract}
Ora, nada é mais certo do que o fato de suprimir virtualmente a minoria não ser uma conseqüência nem necessária e nem natural da liberdade; que, longe de ter qualquer ligação com a democracia, tal fato opõe-se diametralmente ao primeiro princípio desta, ou seja, representação proporcional em números. É uma parte essencial da democracia que as minorias devam ser adequadamente representadas. Nenhuma democracia verdadeira será possível exceto uma falsa demonstração dela sem essas minorias. ${ }^{48}$
\end{abstract}

Nesse passo, os grupos minoritários, no caso em tela, as minorias sexuais ${ }^{49}$, tendo o seu direito a não discriminação quanto à orientação sexual amparado pelo legislador e havendo o reconhecimento constitucional de suas relações, proporcionará efetivamente a inclusão democrática dessas minorias e o tratamento igualitário e protetivo ${ }^{50}$ por parte do poder público.

\begin{abstract}
Assim, minorias devem ter acesso aos canais de formação discursiva da vontade e da opinião pública. Democracia não pode ser vista como tirania da maioria, mas como "el resultado provisional de una permanente formación discursiva de la opinión" (HABERMAS, 1998:247). Segundo Ricoeur (1995:183), a cultura da tolerância significa o "reconhecimento do direito de existir do adversário" ${ }^{51}$
\end{abstract}

Portanto, apesar dos esforços e conquistas do Movimento LGBT Brasileiro em relação à necessidade de aprovação da PL 122/2006, esse projeto é alvo da oposição dos setores mais conservadores do Senado, sendo assim, encontra barreiras para ser aprovado.

Assim, é necessário que a experiência local dos municípios sirva de impulso para mobilizar o Legislador federal em converter a proteção das minorias sexuais em políticas legislativas protetivas e criminalizatórias da violência e discriminação.

\title{
CONCLUSÃO
}

A busca pela garantia e proteção de seus direitos é uma luta constante e extremamente atual das minorias sexuais (LBGT), sendo baseadas no reconhecimento da garantia de direitos em prol do respeito princípio da igualdade, da dignidade da pessoa humana e da não discriminação.

No presente estudo verificou-se a necessidade de mobilização do Legislativo Federal em aprovar o PLC de n. 122/2006, que criminaliza práticas discriminatórias em decorrência da orientação sexual de maneira a proteger as minorias sexuais da violência e do preconceito.

É competência apenas da União em considerar crimes às práticas violentas praticadas por outras pessoas, geralmente grupos de extermínio, às minorias sexuais (LBGT), devendo o Congresso Nacional efetivamente assumir o seu papel 
contra majoritário de maneira a legislar e concretizar os preceitos constitucionais e internacionais relativos à vedação de práticas discriminatórias em decorrência da orientação sexual do ser humano.

Devido à inércia do Poder Legislativo Federal, o Judiciário vem assumindo o seu papel concedendo alguns direitos em determinados $\operatorname{casos}^{52}$.

A omissão do Congresso Nacional denota a oposição de conservadores do Senado bem como vestígios de um pensamento arcaico, excludente e antidemocrático, fora da realidade social do país bem como do compromisso de representatividade que os congressistas assumiram ao se elegerem.

Nesse sentido, o desprezo do legislador em nível federal no trato dessa questão é preocupante, pois nega direitos fundamentais à minorias que os elegeram e que possuem o direito de estarem amparadas pelo poder público.

Os homoafetivos são uma minoria, porém grandiosa, correspondendo a um quarto da população, e, portanto, nada justifica a omissão do legislativo brasileiro em relação aos cidadãos homoafetivos que devem ser alvo de respeito e proteção estatal.

\section{THE LEGISLATIVE INERTIA AND MINORITIES: THE NEED FOR LEGAL PROTECTION HOMOAFETOS}

\section{ABSTRACT}

This study addresses the need for legal protection for sexual minorities with respect to criminalization of discriminatory practices. In the 1988 Constituent Assembly, to prohibit discrimination of any kind, Congress legalized "being" homosexual. Since then, however, little has been done in the Legislature to combat prejudice based on sexual orientation. In its activity, lawmakers continue to ignore the practical consequences of the complete realization of homosexuality, and this fact can be observed before the inertia in the adoption of Bill $n$. 122 aimed at the criminalization of homophobia. Being straight or gay should not lead to any difference in treatment by the state, because without doubt there must be respect for constitutional principles of equality, human dignity, combined with other fundamental values and principles governing the law of Brazil.

Keywords: Criminalization. Equality. Homophobia. Homosexuality. Legal protection.

\section{NOTAS}

Mestranda em Direito Constitucional pela Faculdade de Direito do Sul de Minas. Especialista em Direito Constitucional e Direito Processual Civil pela Faculdade de Direito do Sul de Minas. Bacharel em Direito pela Universidade Presbiteriana Mackenzie. Advogada. E-mail: 
gabybalestero@yahoo.com.br. Endereço: Advocacia e Consultoria - Dra. Gabriela - Rua Coronel Portugual, 107, sala 03 - Centro - CEP 37544-000 - Cachoeira de Mina, MG - Brasil.

** Doutor em Direito Constitucional pela UFMG. Mestre em Direito Constitucional pela UFMG. Professor do Mestrado da Faculdade de Direito do Sul de Minas. Advogado. E-mail: ppgd@fdsm.edu.br. Endereço: Revista da Faculdade de Direito do Sul de Minas. Av. Dr. João Beraldo, 1075 - Centro 37550-000 - Pouso Alegre, MG - Brasil.

DIAS, 2009, p. 48.

DIAS, 2009, p. 48.

3 "A Associação Brasileira de Gays, Lésbicas, Bissexuais, Travestis e Transexuais - ABGLT foi criada em 31.01.1995, com 31 grupos fundadores. Hoje é a maior rede GLBT na América Latina, composta por 203 organizações, sendo 141 grupos de gays, lésbicas, travestis e transexuais, e mais 62 organizações colaboradoras voltadas aos direitos humanos e AIDS. Na assembléia realizada por ocasião da Conferência Nacional, em junho de 2008, foi aprovada a alteração da sigla para LGBTT. A referância inicial é às lésbicas, depois aos gays e aos bisexuais. Os travestis, transexuais e transgêneros são contemplados pelos dois "T". A nova grafia, ao tornar mais visível a homossexualidade feminina, se coaduna com as expressões utilizadas internacionalmente." (DIAS, 2009, p. 49.)

4 "Tal entendimento é esposado internacionalmente pela Organização Mundial de Saúde, por meio de sua Classificação Internacional de Doenças n. 10, em sua última revisão de 1993 (CID 10/1993) e, nacionalmente, pela Resolução 01/1999 do Conselho Federal de Psicologia, e também pela Associação Americana de Psiquiatria desde a década de 1970. Assim, percebe-se que ela é uma das mais livres manifestações da sexualidade humana, ao lado da heterossexualidade. Não é ela uma 'opção' do indivíduo, pelo simples fato de que ninguém escolha em dado momento de sua vida se vai ser homo, hétero ou bissexual: as pessoas simplesmente se descobrem de uma forma ou de outra. Da mesma forma, não se consegue 'trocar' de orientação sexual ao longo da vida - os que se sentem genuinamente atraídos tanto por homens quanto por mulheres (ainda que em gradações diferentes) são bissexuais." (VECCHIATTI, 2008, p. 110/111.)

5 "Como se sabe, a sociedade contemporânea ainda tem muitas reservas com relação a homossexuais. Em decorrência da ignorância e de seus preconceitos sobre o tema, acaba dispensando um tratamento muitas vezes discriminatório com relação a homossexuais - seja por meio de agressões físicas, verbais ou até mesmo pela proibição da manifestação homoafetiva em determinados locais, quando manifestações heteroafetivas idênticas são permitidas. Faz isso por considerar a homoafetividade uma conduta "imoral", que seria passível de reprovação. Ora, se a sexualidade da pessoa dependesse da "opção" dela, qual pessoa escolheria de livre e espontânea vontade ser de uma forma que sofre o repúdio social? Qual pessoa não optaria em mudar para a orientação sexual que não é objeto de preconceitos? Entenda-se bem o que se está dizendo: não se trata de considerar esta ou aquela orientação sexual como "certa", "natural", e assim por diante. Trata-se apenas de afirmar que as pessoas optariam viver da forma mais fácil, sem a dificuldade "extra"do preconceito social. Afinal, aqueles que amam pessoas do mesmo sexo têm, além das mesmas dificuldades cotidianas daquelas que direcionam seu amor a pessoas de sexto diverso, a dificuldade oriunda da discriminação homofóbica, do desprezo social." (VECCHIATTI, 2008, p. 110/111)

6 DIAS, 2009, p. 43/44.

7 'Não há ' sugestionamento' na orientação sexual - o sugestionamento é inócuo, pois não tem nenhuma influência na sexualidade, podendo tê-la apenas na forma como a pessoa se identifica na sexualidade, podendo tê-la apenas na forma como a pessoa se identifica socialmente em termos de sua sexualidade (no apresentar-se como homo, hétero ou bissexual, não no ser homo, hétero ou bissexual)."(VECCHIATTI, 2008, p. 111.)

8 "Se em um extremo estão os países mulçumanos e islâmicos, radicalmente conservadores, no outro estão a Holanda, os países nórticos e mais recentemente a Argentina (restrita a Buenos Aires), como os mais liberais. Entre os conservadores e os liberais está o Brasil, um país com postura intermediária com tendências liberais pelas concessões feitas aos homossexuais." (AMARAL, 2003, p. 17).

9 O PLC 122/2006 ainda não votado pelo Congresso Nacional prevê que serão punidos, na forma da lei os crimes resultantes de discriminação, ou preconceito de raça, cor, etnia, religião, procedência nacional, gênero, sexo, orientação sexual e identidade de gênero, incluindo inclusive a penalização da proibição da manifestação da afetividade em locais públicos. O Projeto de Lei de n. 6.655 B de 21 de fevereiro de 2006 prevê a alteração no art. 58 da lei de registros públicos possibilitando a substituição do prenome das pessoas transexuais. Há 14 anos, foi proposto um projeto de lei de união civil entre pessoas do mesmo sexo (PL 1.151/95), mas, por pressão das bancadas religiosas, o projeto nunca chegou a ser votado e, atualmente, está defasado. Em março de 2009, foi apresentado 
outro projeto de Lei (PL 4.914/2009) que propõe que as mesmas garantias da união estável entre homem e mulher sejam válidas para casais formados por pessoas do mesmo sexo. $O$ projeto que está sendo analisado pelo Comissão de Seguridade Social e Família facilitaria bastante a vida dos casais homoafetivos, principalmente no que se refere à adoção de crianças e adolescentes. Apesar de avançado, o projeto não prevê a conversão da união estável em casamento, o que elimina, por exemplo, o direito dos homossexuais casados de usar o sobrenome de seus companheiros.

10 "A típica família brasileira - patriarcal, matrimonializada e hierarquizada - não escapou ao impacto da modernidade. Sua estrutura foi afetada e modificada por fenômenos que vão da urbanização e da industrialização, passando pelas revoluções tecnológicas, o movimento feminista, os anticoncepcionais e a diminuição da interferência da lgreja, até a instituição do divórcio no Brasil, em 1977. Tudo isso gerou novas espécies de família." (JENCZAK, 2008, p. 89.)

11 "Apesar de não ser reconhecida, há iniciativas e conquistas isoladas nesse sentido. O Tribunal de Justiça do Rio Grande do Sul, por exemplo, reconheceu o direito de herança, em caso de união homoafetiva (Apelação Civil 70001388982 da sétima câmara cível do TJRS). Mas a batalha ainda é muito grande nesse sentido. Para conseguir alguns avanços, é preciso usar argumentos semelhantes aos usados para comprovar as uniões estáveis." (RANGEL, 2010, p. 76.)

12 "Dentre as diversas posições adotadas mundialmente com relação aos direitos dos homossexuais, podemos citar, a título de exemplificação a Dinamarca que foi o primeiro país a conceder direitos a casais homossexuais, em 1989, aceitando, hoje, a parceria registrada entre pessoas do mesmo sexo (o registro do relacionamento de casal homossexual comprometido). Porém, naquele país, não é aceita a adoção de crianças e há a exigência de quem ambos os parceiros sejam dinamarqueses. $O$ mesmo ocorre na Noruega, Islândia e Suécia. A Holanda, em 2001, admitiu o casamento entre pessoas do mesmo sexo, permitindo-lhes a adoção de crianças. Na Inglaterra em 1999, Martin Fitz Patrick e John Thompson foram considerados membros de uma família. Finalmente temos que falar da Argentina, mais especificamente Buenos Aires, onde, em dezembro de 2002, foi aprovada lei permitindo a união civil entre duas pessoas do mesmo sexo. A lei entrou em vigor em abril de 2003 tendo um casal, em julho do mesmo ano, formalizado e legalizado sua união noticiada em jornais de todo o mundo, inaugurando as conquistas concedidas pelo texto legal" (AMARAL, 2003, p.17/18.) VECCHIATTI, 2008, p. 368/369.

14 "Ou seja, a expressão "o homem e a mulher", existente nos dispositivos legais que regulam o casamento civil e a união estável, não pode ser interpretadas de forma proibida do casamento civil e da união estável entre pessoas do mesmo sexo, tendo em vista que estas são pautadas pelo mesmo amor familiar que aquelas. A única interpretação constitucionalmente válida em termos de interpretação conforme para ditos dispositivos é aquele segundo a qual aquela expressão se limita a regulamentar expressamente o direito de duas pessoas de sexos diversos se casarem e manterem união estável sem que isso signifique o não - reconhecimento de tais direitos aos casais homoafetivos." (VECCHIATTI, 2008, p. 369).

15 BAHIA, 2010, p. 90.

16 RIOS, 2002, p. 282.

17 No Estatuto de Igualdade Racial não há previsão de cotas para negros em universidades, empresas e até mesmo nas candidaturas políticas, porém cria a Unilab, ou seja, a Universidade Federal de Integração Luso Afro-Brasileira, que será situada no Ceará na qual proporcionará a integração dos brasileiros com os africanos. PORTO, 2007, p. 7.

19 "O termo homofobia tem sido muito utilizado pela mídia no Brasil e ainda causa algum espanto para alguns, pois se pensa que o sufixo "fobia" teria relação com "medo". Na verdade, "fobia" pode também ser "medo", como "aracnofobia" (medo mórbido de aranhas), mas também pode significar "aversão". Daí que homofobia diria respeito à aversão contra homossexuais." (BAHIA, 2010, n, 240, p. 6)

20 "Ao contrário da 'dificuldade' na aprovação de leis federais em favor dos homossexuais, constatamos que, no nível local, os momentos organizados vêem conseguindo a aprovação de um número significativo de leis, além da constituição de fóruns institucionais de discussão e promoção dos direitos dessa minoria. Em um rápido apanhado, destacamos: - Leis Orgânicas Municipais: Aracaju (art. $2^{\circ}$ ); Campinas (art. 5 XVIII; Florianópolis (art. 5, IV); Fortaleza (art. $7^{\circ}, \mathrm{XXI}$ ); Goiânia $\left(\right.$ art. $1^{\circ}$ ); Macapá (art. $7^{\circ}$ ); Paracatu (art. $7^{\circ}$, VIII); Porto Alegre (art. 150); São Bernardo do Campo (art. 10); São Paula (art. $2^{\circ}$, VIII); Teresina (art. $9^{\circ}$ ); - Legislação Municipal: Belo Horizonte (leis 8.176/01 regulamentada pelo Dec. 10.681/01 - e 8.719/03); Campinas (lei 9.809/98 - regulamentada pelo Dec. 13.192/99 - e lei 10.582/00); Campo Grande (lei 3. 582/98); Goiânia (Res.06/05); Fortaleza (lei 8.211/98); Foz do Iguaçu (lei 2.718/02); Guarulhos (lei 5.860/02); Juiz de Fora (leis 9.789/00 e 10.000/01 e Res. 13/06); Londrina (lei 8.812/02); Maceió (leis 4.667/97 e 4.898/99); Natal (lei 152/97); 
Porto Alegre (Lei Complementar 350/95); Recife (leis 16.730/2001 e 16.780/02 - regulamentada pelo Dec. 20.558/04 - e lei 17.025/04); Rio de Janeiro (leis 2.475/96 e 3.786/02); Salvador (lei 5.275/97); São José do Rio Preto (lei 8.642/02); São Paulo (lei 10.948/01, Dec. 45.712/05, Dec. 46.037/05, Dec. 50.594/06, Orientação Normativa 06/02, Res. SSP 42/00 e 285/00, Port. 08/05; Teresina (lei 3.274/04)." (BAHIA, 2010, p. 101.)

21 "A omissão do Congresso denota resquícios de uma mentalidade arcaica, descolada da realidade social do país e que não encontra eco na Justiça ou no compromisso de representatividade que os congressistas assumiram ao se elegerem. Ao eximir-se da responsabilidade de legislar para os homossexuais, o Legislativo nega direitos a uma parcela importante da população brasileira, que o elegeu. Haverá explicações para essa inação, mas nenhuma delas faz sentido político. A proteção legal das minorias promove e preserva a diversidade e a riqueza social do Brasil. A contribuição dos homossexuais para a construção da nação brasileira é importante e não pode ser ignorada pelo Congresso. Nada, além de preconceito puro e simples e de falta de compromisso com a cidadania do eleitorado, justifica a omissão do Legislativo brasileiro em relação aos direitos dos homossexuais."(PORTO, 2007, p. 7)

"É possível, então, articularmos um discurso sobre discriminação por orientação sexual em minorias? Efetivamente, é possível, na medida em que existe um padrão dominante, ao que o Professor Joaquim Barbosa Gomes se referiu anteriormente. Podemos afirmar que vivemos em uma sociedade branca, masculina, cristã, mas, também, heterossexual, ou, mais modernamente denominado, heterossexista. Portanto, baseado nessa perspectiva, podemos cogitar em minoria." (RIOS, 2001, p. 156.)

23 BAHIA, 2010, p. 90.

24 RIOS, 2001, p. 155.

25 BAHIA, 03 jul. 2010.

26 MOUFFE, 1992, p. 9.

27 "O resultado é a violência nas cidades (meninos de rua, favelados e outros), no campo (posseiros, sem - terra, índios, padres e outros) e contra grupos e minorias (crianças, adolescentes, mulheres, população negra, comunidades indígenas, migrantes nordestinos), como diagnóstico característico dos conflitos em torno dos direitos humanos no Brasil. Esse horror é efetivamente institucionalizado no direito penal pela impunidade sistemática dos agentes estatais e empresariais; e na política e burocracia, pela corrupção. As vítimas não são apenas as pessoas; com elas, vitima-se também a democracia, o Estado de Direito, o Estado de Bem Estar Social, os direitos de defesa contra o Estado bem como, em termos iguais, os direitos de participação, e sobretudo a central 'igualdade perante a lei'." (MILL, 2006, p. 28.)

28 MILL, 2006, p. 63.

29 MILL, 2006, p. 116.

30 HABERMAS, 2007, p. 240.

31 "O liberalismo 1 ignora a equiprocedência das autonomias privada e pública. Não se trata aí apenas de uma complementação que permaneça externa à autonomia privada, mas sim de uma concatenação interna, ou seja, conceitualmente necessária. Pois os sujeitos privados do direito não poderão sequer desfrutar das mesmas liberdades subjetivas enquanto não chegarem ao exercício conjunto de sua autonomia como cidadãos do Estado, a ter clareza quanto aos interesses e parâmetros autorizados, e enquanto não chegarem a um acordo acerca das visões relevantes segundo as quais se deve tratar como igual o que for igual e o desigual o que for desigual." (HABERMAS, 2007, p. 242.)

32 "A política neoconservadora tem uma certa possibilidade de realização se ela encontrar uma base nessa sociedade cindida, segmentada; que ela mesma produz. Os grupos excluídos ou oprimidos à margem não dispõem de nenhum poder de veto, pois representam uma desarticulada minoria segregada do processo de produção. O padrão cada vez mais utilizado no quadro internacional entre a metrópole e a periferia subdesenvolvida parece reiterar-se no interior da sociedade capitalista desenvolvida: os poderes estabelecidos dependem cada vez menos do trabalho e da disposição de cooperação dos empobrecidos e privados de direitos para sua própria reprodução. Entretanto, uma política precisa não apenas poder se impor, ela tem de funcionar também. Mas um abandono definitivo dos compromissos sócio-estatais deixaria, necessariamente, vazios funcionais que só poderiam ser preenchidos através de repressão ou desamparo." (HABERMAS, set. 87, p. 110/111.) HABERMAS, 2007, p. 245/246.

34 "Em primeiro lugar, saliente-se que as proibições de discriminação por este ou aquele critério são entendidas como apelo e recordação de fatores que freqüentemente são utilizados como pretextos injustificados de discriminação, o que não exclui a interdição de outras diferenciações arbitrárias. Deste modo, a ausência de expressa previsão do critério de orientação sexual não é obstáculo para 
seu reconhecimento, não bastasse a explícita abertura constitucional para hipóteses não arroladas explicitamente no texto normativo. Conforme a parte final do artigo $3^{\circ}$, IV, da Constituição da República, a enumeração constitucional convive com a abertura para 'quaisquer outras formas de discriminação'." (RIOS, 2001, p. 71/72.)

"É possível então articularmos um discurso sobre discriminação por orientação sexual em minorias? Efetivamente, é possível na medida em que existe um padrão dominante, ao que o Professor Joaquim Barbosa Gomes se referiu anteriormente. Podemos afirmar que vivemos em uma sociedade branca, masculina, cristã, mas também heterossexual, ou, mais modernamente, heterossexista. Portanto, baseado nessa perspectiva, podemos cogitar em minoria." (RIOS, Roger Raupp; PIOVESAN, Flávia, n. 24, p. 156.).

36 HABERMAS, 2007, p. 250/251.

37 HABERMAS, 2007, p. 253.

38 MÜLLER, 2000, p. 38.

39 HABERMAS, março 1997, p. 93.

40 "Mas a legitimidade pretendida está vinculada, de qualquer modo, à hipótese de que o processo político conducente a maiorias seja um processo do povo na sua totalidade e não apenas de uma vertente política, de um grupo popular, uma comunidade religiosa ou camada social majoritárias ou minoritárias que 'sustentam o Estado' [staatstragend']. Em termos políticos todos devem ter direitos iguais - do contrário a alternância de maioria e minoria não é mais um mecanismo real. Minorias não devem funcionar como bonecos de papel [Pappkameraden] que de qualquer modo serão novamente vencidos pelo voto; em uma sociedade dividida de forma pluralista, elas devem ter uma chance comprovável de se converterem em maiorias. Isso pressupõe que o povo na sua totalidade possa participar efetivamente do processo político." (MÜLLER, 2000, p. 20/21.) HABERMAS, março 1997, p. 97.

42 "No entanto, ambos os problemas se ligam no caso em que o direito prescreve determinadas formas sociais e, com isso, deixa de ser o destinatário das reivindicações por igual consideração de minorias. $\mathrm{O}$ direito torna-se surdo ás exigências de 'diferentes' comunidades à igual consideração quanto à forma de vida (frequentemente, de uma maioria), que é criticada por essas comunidades e que as marginaliza, é ela mesma parte integrante do direito." (FORST, 2010, p. 83.)

43 "No direito brasileiro, o princípio da igualdade formal, coerente com a vocação universal da norma jurídica, proíbe diferenciações fundadas na orientação sexual, impedindo a restrição de direitos fundada exclusivamente na homossexualidade. Além disso, em nossa tradição, o princípio da igualdade material ordena a instituição de igual tratamento entre pessoas e grupos posicionados em situações semelhantes. No âmbito da orientação sexual, a igualdade material institui, na relação entre homossexuais e heterossexuais, o direito a ser tratado igualmente e o dever de dispensar tratamento igual, sempre que não houver fundamentos racionais para a desigualdade. Vale dizer, a diferenciação só pode ser tolerada quando houver fundamentos racionais aptos para sua imposição, em ônus de argumentação tanto maior quanto mais intensa for a desigualdade. São inadmissíveis, desse modo, tratamentos desiguais sem fundamentação racional, baseados em preconceitos ou pontos de vista particulares, ainda que compartilhados por maiorias ou decorrentes do desconforto de quem quer que seja."(RIOS, 2002, p. 177.)

44 FORST, 2010, p. 93.

45 FORST, 2010, p. 69.

46 HABERMAS, 2001, p. 83/84.

47 "A política de tratamento preferencial seria utilitarista se fosse justificada por um acréscimo da utilidade média para a sociedade como um todo e se sacrificasse os direitos individuais a esse fim por exemplo, a discriminação de uma determinada parte da população poderia ser justificada com o argumento do aumento da riqueza social (Dworkin, 1977c, p. 386). O objetivo de criar uma sociedade justa, que está no centro da política de tratamento preferencial, é, contudo, de outro tipo: está baseado não em ponderações utilitárias, mas em ponderações "ideais" sobre uma sociedade justa. Dworkin contesta que a "ação afirmativa" viole os direitos individuais, uma vez que distingue entre um direito a um tratamento igual e, a seguir, um direito a ser tratado como um igual (ibidem, p. 370). O direito a um "tratamento igual" atinge direitos fundamentais, como o direito de votar e o direito a uma educação universal apropriada, mas não o direito de acesso a uma universalidade, por exemplo." (FORST, 2010, p. 98.)

MILL, 2006, p. 116.

BAHIA,2010, p. $89-106$.

50 "Por todo o País, contam-se centenas de Organizações Não - Governamentais de defesa de LGBT. Sua atuação é eminentemente local, daí sua importância quando se fala na proteção contra discriminação no âmbito dos Municípios. Em sociedades descentradas, sem grandes vínculos de 
tradição e, aparentemente, refratária à política, é um dado sobremaneira interessante perceber como esses movimentos possibilitam a (re)produção da idéia de 'identidade de grupo'. Assim, apesar de locais, não se pode negar que essas ONGs estão entre os movimentos mais atuantes pela defesa de Direitos Humanos na atualidade e do que se pode denominar hoje "sociedade civil organizada". (BAHIA, 2010, p. 102.)

BAHIA; MORAES, 2010, p. 427.

Nos casos de adoção, tem prevalecido nas decisões do Superior Tribunal de Justiça, o melhor interesse da criança. Baseado nesse princípio a Quarta Turma proferiu em 27 de abril de 2010 uma decisão inédita: permitiu a adoção de crianças por um casal homossexual, lésbicas.

\section{REFERÊNCIAS}

AMARAL, Sylvia Mendonça do. Manual Prático dos Direitos de Homossexuais e Transexuais. São Paulo: Edições Inteligentes, 2003.

BAHIA, Alexandre Gustavo Melo Franco. A não - discriminação como direito fundamental e as redes municipais de proteção a minorias sexuais - LGBT. Brasília: Revista de Informação Legislativa, a.47, n. 186 abr./jun.2010, p. 89 -106.

BAHIA, Alexandre Gustavo Melo. Casamento, um direito civil. A Tribuna Pousoalegrense, Pouso Alegre, v. 242, p. 6 - 6,17 jul. 2010.

BAHIA, Alexandre Gustavo Melo Franco. Homofobia no Brasil. A Tribuna Pousoalegrense: Pouso Alegre, v. 240, p. 6 - 6, 03 jul. 2010.

BAHIA, Alexandre Gustavo Melo Franco. Nem pai, nem mãe: o melhor interesse da criança acima de tudo. Jornal A Tribuna Pousoalegrense: Pouso Alegre - MG, v.238, p. 6 - 6, 19 jun. 2010.

BAHIA, Alexandre Gustavo Melo Franco. MP, Interessante Público e Melhor Interesse da Criança. Jornal A Tribuna Pousoalegrense: Pouso Alegre - MG, v. 248, p. 6 - 6, 28 ago. 2010.

BAHIA, Alexandre Gustavo Melo Franco; MORAES, Daniel. Discriminaçao contra minorias sexuais, religiao e o constitucionalismo brasileiro pos-88. Revista General de Derecho Constitucional (Internet), v. 10, p. 409/431, 2010.

DIAS, Maria Berenice. União homoafetiva: o preconceito e a justiça. 4. ed. São Paulo: Revista dos Tribunais, 2009.

FORST, Rainer. Contextos da Justiça. Boitempo Editorial: São Paulo, 2010.

GRANATO, Eunice Ferreira Rodrigues. Adoção doutrina e prática: com abordagem do novo código civil 1. ed. Curitiba: Juruá Editora, 2004.

JENCZAK, Dionízio. Aspectos das relações homoafetivas à luz dos princípios constitucionais. Florianópolis: Conceito Editorial, 2008.

HABERMAS, Jürgen. A Constelação Pós - Nacional: ensaios políticos. São Paulo: Littera Mundi, 2001. 
HABERMAS, Jurgen. A inclusão do outro. São Paulo: Edições Loyola, 2007.

HABERMAS, Jürgen. A nova intransparência: a crise do Estado de Bem Estar Social e o Esgotamento das Energias Utópicas. Novos Estudos: CEBRAP, n.18, set. 87, p.77 -102.

HABERMAS, Jurgen. Entrevista de Jurgen Habermas a Mikael Carlehedem e René Gabriels. Novos Estudos CEBRAP, n. 47, março 1997, p. 85-102.

PORTO, Alexandre Vidal. O Congresso e os homossexuais. Opinião. O Globo, 21/09/2007, p. 7.

MILL Stuart. Ensaio sobre a Liberdade. São Paulo: Escala, 2006.

MILL Stuart. O Governo Representativo. São Paulo: Escala, 2006.

MOUFFE, Chantal. Pensando a democracia com, e contra, Carl Schmitt. Trad. Menelick de Carvalho Neto. In Revue Française de Science Politique, vol.42, n.1, fev.1992.

MÜLLER, Friedrich. Que grau de exclusão social ainda pode ser tolerado por um sistema democrático? Porto Alegre: Unidade editorial, 2000.

RANGEL, Vera Lígia. Conheça e Defenda seus Direitos. São Paulo: Nova Cultural, 2010.

RIOS, Roger Raupp. A homossexualidade no direito. Porto Alegre: Livraria do Advogado, Esmafe, 2001.

RIOS, Roger Raupp. O princípio da igualdade e a discriminação por orientação sexual: a homossexualidade no direito brasileiro e norte americano. São Paulo: Revista dos Tribunais, 2002.

RIOS, Roger Raupp; PIOVESAN, Flávia. A discriminação por gênero e por orientação sexual. In Seminário Internacional: as minorias e o direito, 2001, Brasília. Anais. Brasília: Série Cadernos do CEJ, v. 24, p. 154 - 175.

VECCHIATTI, Paulo Roberto. Manual da Homoafetividade: da possibilidade jurídica do casamento civil, da união estável e da adoção por casais homoafetivos. São Paulo: Método, 2008.

Site: www.naohomofobia.com.br

Recebido para publicação: 06/06/2010

Aceito para publicação: 23/12/2010 